\title{
BANTUAN TEKNIS PELAKSANAAN PENGECATAN BALAI RW XI JALAN SILIKAT KELURAHAN PURWANTORO KECAMATAN BLIMBING KOTAMADYA MALANG
}

\author{
Oleh: \\ Udi Subagyo ${ }^{1)}$,Nain Dhaniarti Raharjo. R, Achendri M.Kurniawan,Moch. Khamim,Boby \\ Asukmajaya Raharjo \\ Jurusan Teknik Sipil, Politeknik Negeri Malang ${ }^{1)}$ \\ udi_subagyo@yahoo.com.
}

\begin{abstract}
Balai $R W$ is a construction or building used by residents for $R T$ activities or activities of local residents and has been built since 1998 and is used as a place for local residents' activities. For the condition of the Balai RW XI in 2020 today, there are many that are not suitable for use, especially in wall construction, where many conditions are damp and the wall paint is peeling off so that repairs are needed in the form of painting the outer and inner walls. Implementation of Community Service Painting of Balai RW XI Jl. Silikat Kel.. Purwantoro Kec. Blimbing Malang city is carried out are: 1. Calculation of the Budget Plan for Painting Implementation Costs Balai RW XI is Rp. 13,955,000, - (Thirteen Million Nine Hundred Fifty Five Thousand Rupiah) the source of funds from PKM Polinema activities and RW XI Cash. 2. Painting the Balai RWXI is prioritized on repairing inner and outer wall paints. 3. Implementation of painting at Balai $R W X I$ will be carried out from 20 July 2020 - 8 August 2020 with a total processing time of 3 weeks.
\end{abstract}

Key words: PKM, Balai RW, wall painting

\section{PENDAHULUAN}

1.1 Analisis Situasi

Balai RW adalah suatu konstruksi atau bangunan yang digunakan oleh warga untuk kegiatan RT ataupun kegiatan warga setempat dan sudah dibangun sejak tahun 1998 dan digunakan untuk kegiatan :

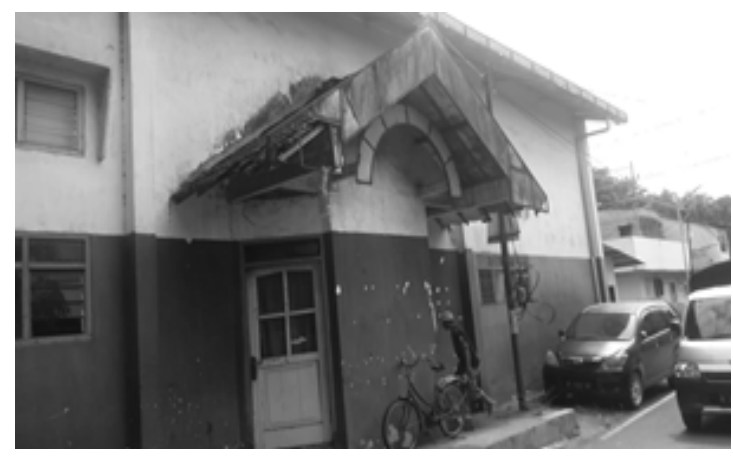

Gambar 1.Kondisi sebelum

1.Untuk masyarakat umum

-Sebagai tempat kegiatan warga setempat yang berupa :
- Tempat Kegiatan Pertemuan warga

-Tempat Kegiatan Resepsi warga

-Tempat Kegiatan POSYANDU

-Tempat Kegiatan Olah Raga Bulu Tangkis warga

-Dengan dipakainya tempat tersebut untuk warga setempat maka dapat mengatasi permasalahan warga yang berupa tempat untuk bersosialisasi dan berkegiatan warga.

- Permasalahannya yang khusus warga yaitu kesulitan tempat untuk menggadakan resepsi karena keterbatasan lahan dapat terselesaikan.

2. Untuk masyarakat calon wirausaha

Dengan adanya balai RW yang repre sentative maka akan membuat potensi pemasukan Kas RW dari kegiatan usaha penyewaan tempat untuk resepsi, badminton dan usaha yang lainnya.

Oleh karena itu setiap daerah di kotamadya Malang hampir semua memiliki gedung balai RW. Sedangkan balai RW yang ada minim perawatan dan cenderung kotor 
dan mulai rusak, yang mana banyak cat dinding luar maupun dalam sudah mulai rusak. Kondisi balai RW XI tersebut pada tahun 2020 sekarang ini, terdapat banyak yang kurang layak digunakan, terutama pada kostruksi dinding, dimana banyak kondisi dinding yang lembab dan cat dinding terkelupas sehingga diperlukan perbai kan.berupa pengecatan dinding. Karena hal tersebut diatas Pengurus RW XI berkeinginan merencanakan memperbaiki secara menye luruh, sehingga kondisi balai RT tersebut layak digunakan kegiatan warga sekitar Pengecatan interior dan eksterior Balai RW XI tersebut memerlukan biaya yang tidak sedikit. Hal ini tentunya harus menjadi bahan pertimbangan dalam proses renovasi.

\subsection{Permasalahan Mitra}

Berdasarkan analisis situasi tersebut di atas untuk pelaksanaan pengecatan Balai RW XI J1. Silikat Kel. Purwantoro Kec. Blimbing kota Malang diperlukan perencanaan anggaran biaya dan pengawasan pelaksanaan secara baik. Dan permasalahan yang dimiliki oleh pengurus RW XI Kel. Purwantoro Kec. Blimbing tidak mempunyai tim teknis yang dapat mengelola pelaksanaan perawatan gedung tersebut sehingga perawatan yang ada hanya berupa perawatan tambal sulam sesuai dengan apa yang dibutuhkan.

Saat ini, di era perdagangan global baik di dalam maupun di luar negeri persaingan bisnisnya semakin meningkat ketat. Menurut Kotler (2005) dalam Samboro, et. al (2019) menyebutkan pemasaran adalah suatu proses sosial dan manajerial dengan mana perseorangan atau kelompok memperoleh apa yang mereka butuhkan dan inginkan melalui pembuatan, pertukaran produk yang bernilai bagi pihak lain. Dalam pemasaran terdapat suatu kegiatan atas produk yang dihasilkan suatu usaha yaitu berupa pemvberian merek. Pengertian merek sebagai bagian dari Hak Milik Intelektual tidak terlepas dari pemahaman bahwa hak merek diawali dari temuan-temuan dalam bidang Hak Kekayaan Intelektual lainnya, misalnya hak cipta (Sulastri, et. al, 2018). Sejak ratusan tahun mereke telah dipakai guna memberikan ciri pada produk yang telah dihasilkan dengan tujuan untuk menunjukkan asal usul barang (indication of origin). Merek adalah alat pembeda produk dan juga sebagai petunjuk kualitas suatu produk selain itu juga sebagai pengenal atau identitas yang akan memudahkan konsumen untuk memutuskan pilihannya membeli atau tidak membeli. Jika produk tidak mempunyai merek, maka otomatis tidak akan dikenal atau dibutuhkan konsumen, oleh karena itu suatu produk apakah produk itu baik atau tidak, pasti akan memakai merek tertentu. Merek berpengaruh terhadap Keputusan Pembelian Konsumen pada Produk Makanan di UMKM (Mulyadi, 2015). Hal ini sejalan dengan Kusmawati \& Samboro (2015) yang menyatakan bahwa disamping faktor psikologis ternyata faktor ekuitas merek juga berpengaruh terhadap keputusan pembelian. Oleh karena itu, merek suatu produk berperan penting untuk menunjang suatu usaha.

Pengabdian kepada Masyarakat yang berlokasi RT 14 RW 09 Kelurahan Peduru ngan Tengah Semarang, dengan kalayak sasaran UKM di wilayah RT 14 RW 09 Kelurahan Pedurungan Tengah, yang mana dalam wilayah tersebut terdapat beberapa usaha yang produknya dihasilkan oleh ibuibu rumah tangga yang berkeinganan untuk menambah penghasilan keluarga terutama pada masa pandemi Covid 19 sekarang ini sehingga dapat meningkatklan kesejahteraan keluarga. Salah satu hasil produknya adalah makanan yaitu Lunpia, peyek kacang, peyek teri dan Roti Bolen. Penjualannya ditawar kan melalui teman atau saudara untuk dijual kembali.

Selanjutnya, pelaku usaha juga perlu diberikan penyuluhan mengenai pentingnya pemberian merek pada produk yang dimiliki, karena selain sebagai tanda pembeda, merek juga memiliki fungsi penting sebagai hak kepemilikan agar merek yang dimiliki terhindar dari penjiplakan/peniruan oleh pelaku usaha lain. Fungsi inilah yang belum diketahui oleh pelaku usaha sebagai legaitas merek, karena berdasarkan pemahaman pelaku usaha merek hanya sekedar tanda pembeda saja. Menurut Wijayanti, et. al (2020) menyatakan bahwa beberapa pelaku usaha menempatkan merek produk yang telah mereka pilih namun belum dicantumkan pada kemasan sehingga tidak memiliki keunggulan untuk bersaing di pasaran.

Saat ini, UMKM merupakan porsi terbesar dari kegiatan perekonomian masyarakat. Meskipun merupakan penyela 
mat ekonomi nasional, UMKM memiliki masalah yang menghambat pertumbuhannya (Sudarwati \& Satya, 2013).

Pengabdian kepada Masyarakat yang akan dilaksanakan fokus pada pelaku usaha UKM di RT 14 RW 09 Kelurahan Pedu rungan Tengah Semarang sebagai target program dengan tujuan agar pelaku usaha UMK mendapatkan pemahaman mengenai pentingnya merek bagi suatu produk sebagai sehingga pemahaman tersebut dapat diterapkan dalam kegiatan usaha serta dapat memperbaiki kualitas usaha yang sedang dijalankan. Sampai sekarang UKM di RT 14 RW 09 Kelurahan Pedurungan Tengah menghadapi masalah uyaitu belum memaha mi tentang pentingnya merek untuk suatu produk terutama untuk produk yang ada pesaingnya atau bukan produk tunggal.

\section{KAJIAN LITERATUR}

\subsection{Rencana Anggaran Biaya (RAB)}

Rencana Anggaran Biaya adalah suatu kegiatan perhitungan untuk menda patkan jumlah biaya yang diperlukan untuk suatu kegiatan yang didasarkan atas informasi yang tersedia pada waktu itu (Bachtiar, 1993). Biaya biaya yang terdapat dalam penyusunan rencana anggaran biaya adalah sebagai berikut :

1. Biaya langsung (Direct Cost)

Biaya langsung adalah biaya untuk segala sesuatu yang akan menjadi komponen permanent hasil akhir proyek (Soeharto, 1995). Biaya langsung terdiri dari biaya pengadaan material, upah pekerja atau buruh, biaya peralatan dan biaya sub kontraktor.

2. Biaya Tidak Langsung (Indirect Cost)

Biaya tidak langsung adalah biaya pengeluaran untuk manajemen, supervisi dan jasa untuk pengadaan bagian proyek yang akan menjadi instalasi atau produk permanen, tetapi diperlukan dalam rangka proses pembangunan (Soeharto, 1995). Yang termasuk di dalamnya adalah : Kontingensi, Overhead office, Overhead site, pajak (PPN), keuntungan dan biaya perijinan.

\subsection{Kuantitas Pekerjaan}

Kuantitas pekerjaan adalah jumlah atau volume suatu pekerjaan yang dihitung berdasarkan gambar bestek sesuai dengan satuannya. Dalam perhitungan kuantitas pekerjaan, biasanya tergantung pada pengelompokan pekerjaan berdasarkan jenis pekerjaanya. Dalam setiap pekerjaan terdapat perbedaan satuan seperti berikut :

$\mathrm{m}$ '= meter panjang untuk pekerjaan benangan $\mathrm{m} 2=$ meter persegi contoh : untuk pekerjaan siaran pasangan batu

$\mathrm{m} 3=$ meter kubik contoh : untuk pekerjaan galian dan timbunan

$\mathrm{Kg}=$ Kilogram contoh untuk pekerjaan pembesian

LS = Lump Sump untuk pekerjaan yang tidak dapat diketahui secara pasti cara memperoleh kuantitasnya, contohnya : mobilisasi, perijinan.

\subsection{Harga Satuan Pekerjaan (HSP)}

Harga satuan pekerjaan adalah biaya yang dibutuhkan untuk menyelesaikan satu satuan pekerjaan yang meliputi :

1. Biaya Tenaga Kerja atau Upah Kerja :

a. Harga/tarif upah kerja per satuan waktu (Rp/jam, Rp/hari)

b. Produksi hasil kerja per satuan waktu (m3/jam, lembar/hari)

2. Biaya Material

a.Harga material per satuan volume/berat/unit (Rp/liter, $\mathrm{Rp} / \mathrm{m} 3$ )

b. Kuantitas material yang dibutuhkan per satuan pekerjaan $\left(25\right.$ piece $/ \mathrm{m}^{\prime}, 50 \mathrm{~kg} / \mathrm{m} 3$ beton dan sebagainya)

c. Termasuk kehilangan dan kemungkinan kerusakan (losser) per satuan pekerjaan yang bersangkutan.

3. Biaya Peralatan

a. Harga/tarif sewa alat per satuan waktu (Rp/jam, Rp/bulan)

b.Harga/ tarif biaya investasi (biaya penyusutan) alat per satuan waktu, kalau alat milik sendiri (investasi) (Rp/jam)

c. Biaya operasional alat per satuan waktu (Rp/jam)

Jika biaya pekerjaan terdiri dari beberapa unsur biaya tersebut di atas, maka perhitungan biaya dari unsur unsur biaya tersebut digabungkan. Apabila karena alasan tertentu, harus memperhitungkan biaya biaya lain yang tidak langsung merupakan biaya pekerjaan yang bersangkutan, maka umumnya biaya biaya tersebut bisa termasuk atau terakomodasi dalam " contingencies cost " dan/atau " mark up " serta beberapa unit price pekerjaan yang memungkinkan untuk memfasilitasi hal tersebut (Sultan Syah. 2004). Harga satuan pekerjaan dapat dirumuskan sebagai berikut :

HSP = koefisien $\mathrm{x}$ harga satuan pasar 
Dimana :

Koefisien $=\quad$ angka $\quad$ pengali $/$ kuantitas sumberdaya

Harga Satuan pasar = Harga upah dan bahan yang berlaku pada waktu HSP dibuat

\section{METODE}

Metode pelaksanaan sebagai berikut :

1.Berkoordinasi dengan pengurus pengecatan Balai RW

2.Menggambar sesuai hasil koordinasi dengan pengurus Balai RW

3.Setelah bentuk perbaikan diketahui dimensi, arahnya dan letaknya, kemudian proses penggambaran, gambar tampak dan lain-lain.

4.Menentukan spesifikasi teknisnya, kemudian menghitung volume dari masing-masing item pekerjaan untuk kemudian digunakan menghitung harga satuan bahan dan upah dengan hasil akhir berupa rencana anggaran biaya (RAB).

5.Pembuatan jadwal pelaksanaan (Time Schedulle).

6.Penyerahan hasil gambar (design) perencanaan pembangunan saluran berikut rencana anggaran biaya (RAB) dan waktu pelaksanaan (Time Schedulle) kepada pihak pengurus Balai RW

7.Koordinasi untuk pengawasan perbaikan Balai RW sesuai dengan rencana yang ada.

\section{HASIL DAN PEMBAHASAN}

\subsection{Rencana Anggaran Biaya (RAB)}

Hasil perhitungan anggaran dan biaya

Pengecatan adalah sebagai berikut :

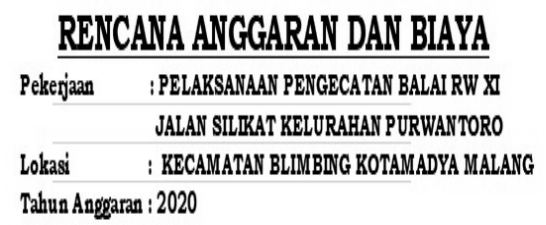

\begin{tabular}{|c|c|c|c|c|c|}
\hline \multirow{2}{*}{ NO. } & \multirow{2}{*}{ URAIAN PEKERJAAN } & \multirow{2}{*}{ VOL. } & \multirow{2}{*}{ SAT. } & \multirow{2}{*}{$\begin{array}{l}\text { HARGA } \\
\text { SATUAN }\end{array}$} & \multirow{2}{*}{ JUMLAH } \\
\hline & & & & & \\
\hline 1 & 2 & 3 & 4 & 5 & 7 \\
\hline & & & & & \\
\hline I. & PEKERJAAN PENGECATAN & & & & \\
\hline 1 & Mobilisassi dan Persiapan & 1.00 & Ls & $384,000.0$ & $\operatorname{Rp} 384,000.00$ \\
\hline 2 & Pembershihan dan Penoupasan dinding dalam & 26500 & M2 & 2600.0 & $\operatorname{Rp} \quad 689,000.00$ \\
\hline 3 & Pembershand dan Penguvasann dinding luar & 156.00 & N2 & $2,601.0$ & $\operatorname{Rp} \quad 405,756.00$ \\
\hline 4 & Pengecatan Dinding Dalam & 265.00 & M2 & $24,3000.0$ & Rp 6,439,500,00 \\
\hline 5 & Pengecalan Dinding Lua & 15600 & N2 & 387000.0 & Rp 6,037,200.00 \\
\hline
\end{tabular}

\subsection{Pelaksanaan Pengecatan}

Pelaksanaan pekerjaan Pelaksanaan Pengecatan Balai RW XI Jl. Silikat Kel. Purwantoro Kec. Blimbing dilakukan mulai tanggal 20 Juli 2020 - 08 Agustus 2020, adapun rincian pekerjaan tersebut adalah sebagai berikut :

1.Minggu I Tanggal 20 Juli 2020 -25 Juli 2019 kegiatan awal pekerjaan yang meliputi : Persiapan peralatan dan material yang dibutuhkan, pekerjaan pembersihan serta pengupasan bagian bagian yang rusak, Pelapisan plamir pada dinding dan tembok

2.Minggu II Tanggal 27 Juli 2020 -08 Agustus 2020 dilakukan kegiatan pengecatan inding dalam dan dinding Luar
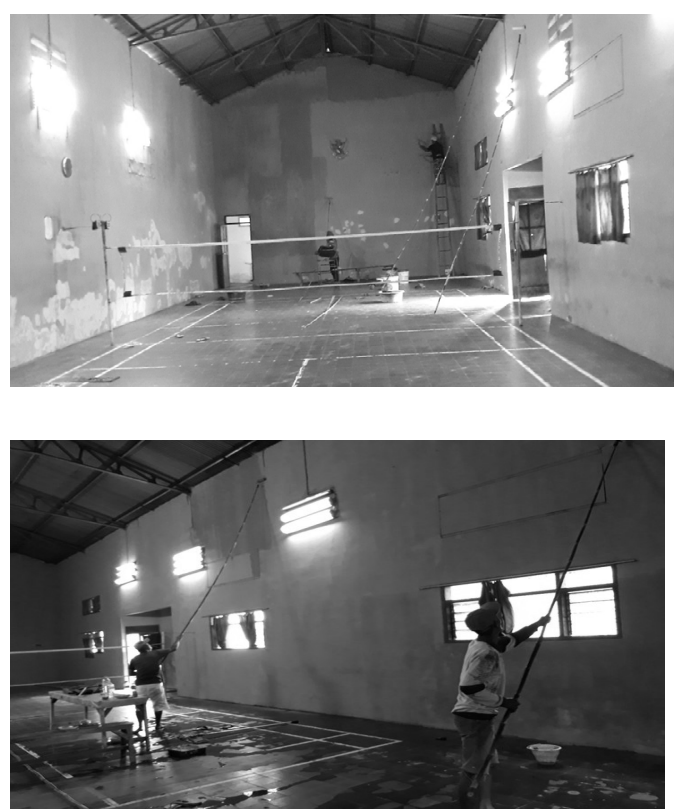

Gambar 3.Pekerjaan Pengupasan dan pelapisan plamir dinding

\subsection{Manfaat}

Manfaat langsung dari kegiatan PKM ini adalah hasil pekerjaan Pengecatan Balai Balai RW XI Jl. Silikat Kel. Purwantoro Kec. Blimbing

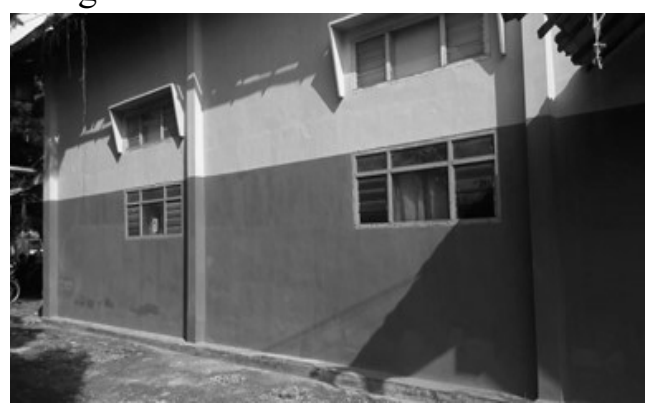




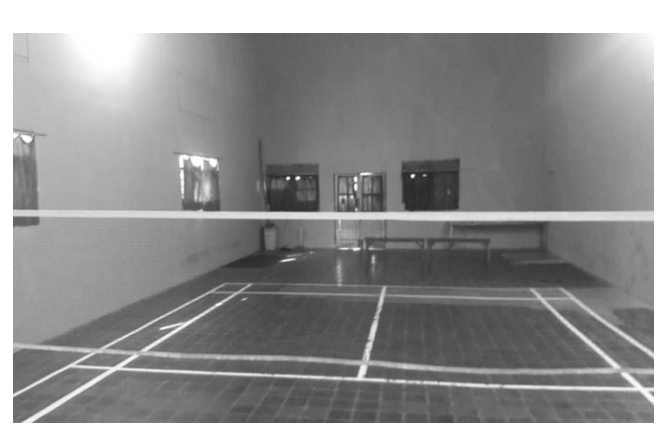

Gambar 5.Kondisi Sesudah Kegiatan

\section{KESIMPULAN}

Pelaksanaan Pengabdian Kepada Masyarakat untuk pekerjaan Pengecatan Balai Balai RW XI Jl. Silikat Kel. Purwantoro Kec. Blimbing dilakukan adalah :

a. Disain pekerjaan Pelaksanaan Pengecatan Balai RW XI J1. Silikat Kel. Purwantoro Kec. Blimbing di utamakan pada perbaikan Cat dinding dalam dan dinding luar.

b. Besarnya Rencana Anggaran Biaya
Pelaksanaan Pengecatan Balai RW XI Jl. Silikat Kel. Purwantoro Kec. Blimbing sebesar Rp. 13.955.000,- ( Tiga Belas Juta Sembilan Ratus Lima Puluh Lima Ribu Rupiah) sumber dana dari kegiatan PKM Polinema dan Kas RW XI.

c. Pelaksanaan Pelaksanaan Pengecatan Balai RW XI Jl. Silikat Kel. Purwantoro Kec. Blimbing dilakukan mulai tanggal $20 \mathrm{Juli}$ 2020 - 08 Agustus 2020 dengan total waktu pengerjaan 3 minggu.

\section{DAFTAR REFERENSI}

Soeharto, Iman. 1995. Manajemen Proyek (Dari Konseptual sampai operasional) Jakarta : Penerbit Erlangga.

Ibrahim, Bachtiar. 1993. Rencana dan Estimate Real of Cost. Jakarta : Bumi Aksara

Sultan, Syah Mahendra. 2004. Manajemen Proyek Kiat Sukses Mengelola Proyek. Jakarta. Gramedia Pustaka Utama. 